\title{
Editorial
}

\section{Chemistry, Physics, and Biology of Water}

\author{
Oleksandr A. Loboda ${ }^{1,2}$ and Vladyslav V. Goncharuk ${ }^{2}$ \\ ${ }^{1}$ Université de Lorraine, CNRS, SRSMC UMR 7565, 54506 Vandouvre-lès-Nancy Cedex, France \\ ${ }^{2}$ A.V. Dumansky Institute of Colloid and Water Chemistry, National Academy of Sciences, Boulevard Vernadsky 42, Kyiv 142, Ukraine
}

Correspondence should be addressed to Oleksandr A. Loboda; loboda@kth.se

Received 27 October 2013; Accepted 27 October 2013

Copyright (c) 2013 O. A. Loboda and V. V. Goncharuk. This is an open access article distributed under the Creative Commons Attribution License, which permits unrestricted use, distribution, and reproduction in any medium, provided the original work is properly cited.

The aquatic sciences become more important to the research and the public. Water affects almost every aspect of our lives and causes a tremendous interest in its properties. For thousands of years people used to drink only natural water. First water pipelines were made with wood and granite and it was satisfactory because these materials are natural. After replacement of such natural materials by anthropogenic one the new threats to the human health appeared. For instance, ancient Romans used lead pipes and lead tableware which was often the cause of poisoning. This is one of the examples of consequences of anthropogenic approach to a water-supply system and utilization of toxic water. However, the awareness of the whole severity of the problem came only in the 20th century. More than 150 years ago the global industrialization started; megalopolises emerged leading to environmental pollution and numerous ecological problems. The rapid industrial growth prompted people to use chemical reagents for surface water in order to produce drinking water. In 1853 first standards for drinking water were established. By that time the pollution of surface water sources was not so dramatic, therefore, the quality of drinking water was determined only by 9 components. Over past decades chemical composition of water has changed. A vast amount of anthropogenic components have been released into the environment; these substances were made artificially by people and never existed in nature. In peer-reviewed publications more than 35 million of such anthropogenic components were found. Moreover per one year near one and a half millions of new compounds are synthesized and all of them could be found in aqueous medium. Majority of surface water which provides a centralized water supply is characterized by chemical and bacteriological pollution. It should be noted that among other pollutants the antibiotics are the most dangerous as far as they sterilize the water. Therefore, we hope that the topic of this special issue arrives at a good time and will be of interest for the broad range of readership.

This special issue aims to (a) present new insights in the multifold of data on chemical, physical, and biological properties of water, (b) characterize the state of the water resources, and (c) estimate the quality of natural water and the anthropogenic impact on the water environment. The particular attention paid in this special issue is to the resistance degree of biosystems in respect to the influence of chemical, physical, and some other factors. The general focus of the issue is on the systematic fundamental and applied research work in chemistry, physics, and biology of water.

Of course, the selected papers are not able to fully cover the topic of this special issue; nonetheless they represent the rich and many-faceted knowledge that we are pleased to share with the readers.

This special issue contains six papers, where three papers are related to the oxidation processes and one paper elucidates effective technique for absorption of heavy metals from the wastewaters. The remaining two papers are devoted to the problems of water quality, review the state of the water resources, describe the consequences of the anthropogenic impact on the water environment, and finally address the drinking water standard issue.

In paper entitled "Fenton-like oxidation of malachite green solutions: kinetic and thermodynamic study," J. Hashemian presents oxidation by Fenton-like reactions which is proven to be economically feasible process for destruction of a variety of hazardous pollutants in wastewater. In this study, the 
degradation and mineralization of malachite green dye is reported using Fenton-like reaction. The results of experiments showed that the degradation of malachite green dye in Fenton-like oxidation process can be described with a pseudo-second-order kinetic model. It has been shown that the oxidation process occurs spontaneously and endothermically. The obtained results are claimed to be useful for designing the treatment systems of various dye-containing wastewaters.

In the paper entitled "Photocatalysis: oxidative processes in water treatment," N. M. Soboleva and R. V. Prihod'ko consider the efficiency of photocatalytic oxidation of various organic compounds. It is shown that photocatalytic methods can significantly increase the speed and depth of decomposition processes of intoxicants. The use of photocatalysis in the creation of low-power water treatment technologies has been concluded by authors as a promising direction in addressing environmental problems of the hydrosphere.

Shvadchina et al's paper deals with "Evaluation of efficacy of anionic surfactant degradation in the presence of concomitant impurities of natural waters". Y. Shvadchina et al. define the most efficient method of destruction of anionic surfactants in the presence of humic acids and natural organic matter of river waters. Comparison of efficiency of destruction of anionic surfactant-sodium alkylbenzene sulfonate (ABS) in model aqueous solutions by various oxidation methods showed that photocatalytic ozonation is the most effective method of ABS removal from waters containing humic acids or natural organic matter and bicarbonate-ions. Along with a maximum reduction of $\mathrm{ABS}$ concentration photocatalytic ozonation also ensured the highest degree of mineralization of organic impurities of all model solutions and river waters.

In the paper entitled, "Layered double hydroxides as effective adsorbents for $U(V I)$ and toxic heavy metals removal from aqueous media," G. Pshinko explores high effective adsorbents for $\mathrm{U}(\mathrm{VI})$ and other toxic heavy metals in aqueous solution on the basis of layered double hydroxides. The author shows that such adsorbents may be used for sorption of cationic and anionic forms of $\mathrm{U}(\mathrm{VI})$ within a technology of purification of highly mineralized water containing carbonate ions. The optimal conditions have been established for adsorption processes, and the studied adsorbents have been shown to be used as potential adsorbents for the recovery of $\mathrm{U}(\mathrm{VI})$ and other heavy metals from wastewater of mining and processing plants and other waters containing toxic metals.

V. V. Gonchatuk's paper presents a comprehensive review on "Water as the earth's buffer and immune system." The author highlights the relationship between the quality of drinking water and the level of development of human intelligence and its health. The problems of obtaining cytogenetically and physiologically safe high-quality drinking water are discussed along with the problems of its decontamination. The solutions to maintain stable development of aquatic ecosystems are proposed. It is shown that tap water is the habitat of multiresistant genetically mutated microorganisms.

In the final V. V. Goncharuk's paper, he proposes "The new standard for drinking water." The author performs analysis of modern critical situation with a quality of drinking water in the world. The author argues and justifies the inefficiency of existing approaches to the assessment of drinking water in the world. The research work of V. V. Goncharuk reveals the core statements of a new standard for drinking water whereas the key advantage of a new standard is the inclusion to it the integral control methods for the water quality, which is universal for all kinds and types of toxic compounds, irrespective of their origination and type of action.

\section{Acknowledgments}

We would like to express our gratitude to the authors for their valuable contributions. Finally, we would like to acknowledge and to thank all reviewers for their criticism, comments, and suggestions.

Oleksandr A. Loboda Vladyslav V. Goncharuk 

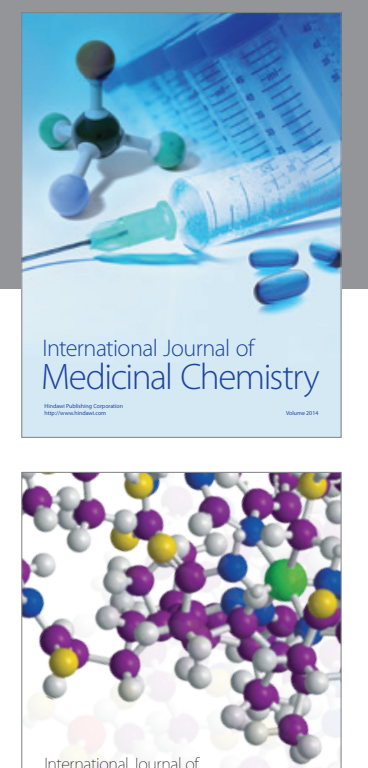

\section{Carbohydrate} Chemistry

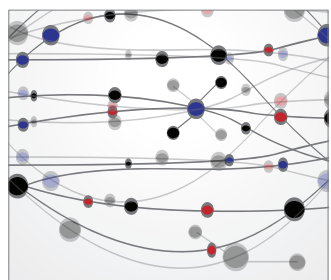

The Scientific World Journal
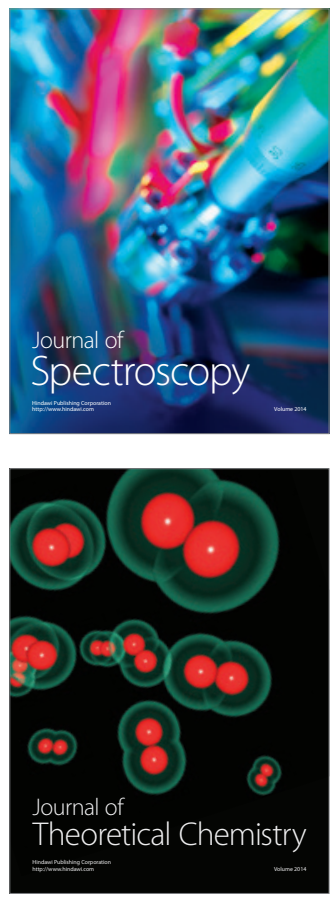
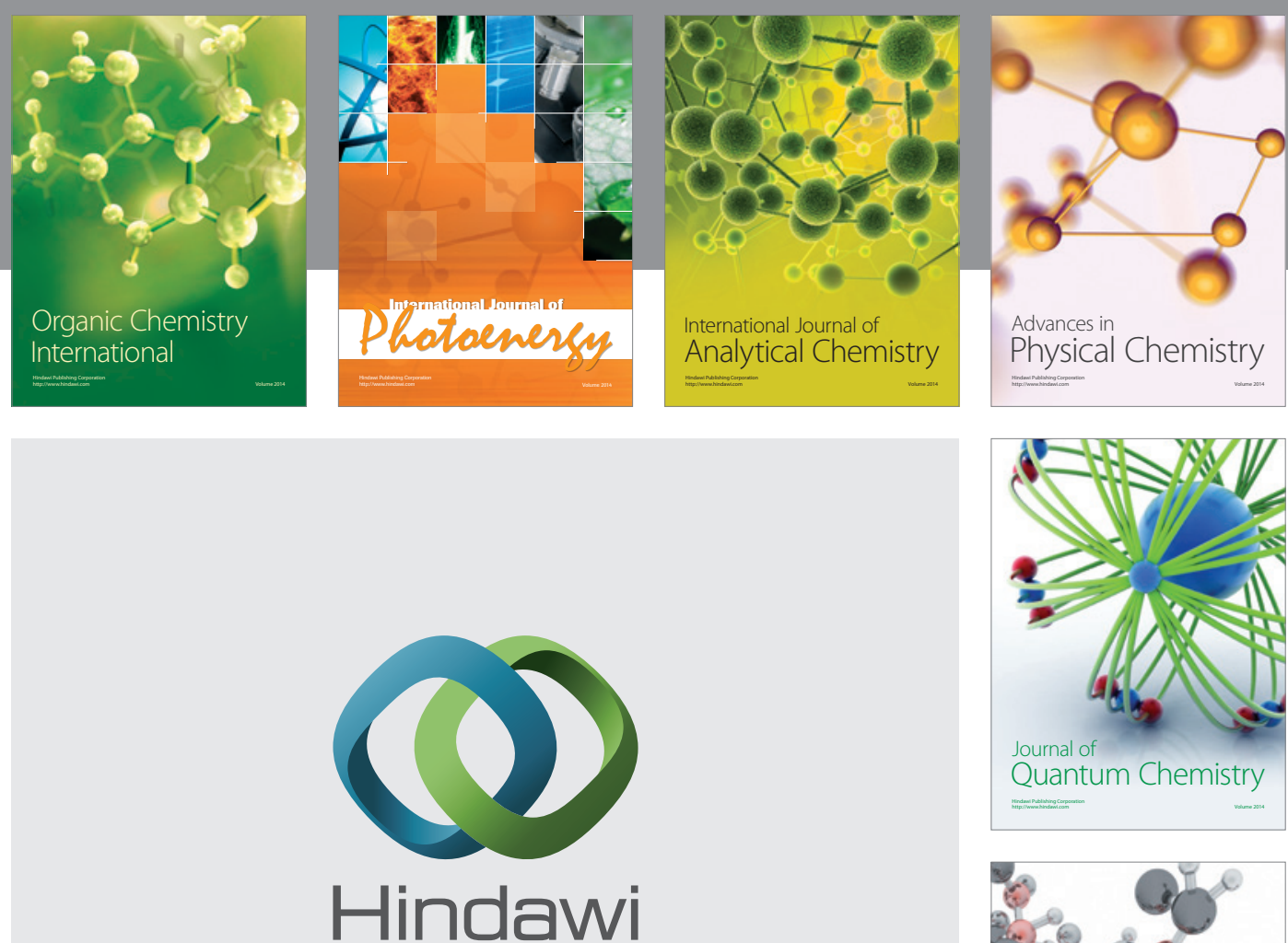

Submit your manuscripts at

http://www.hindawi.com

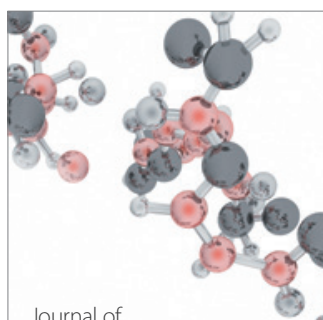

Analytical Methods

in Chemistry

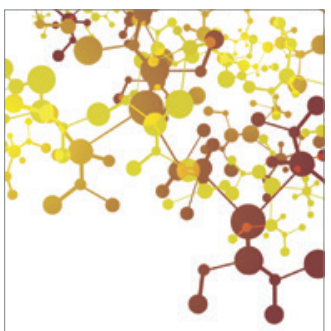

Journal of

Applied Chemistry

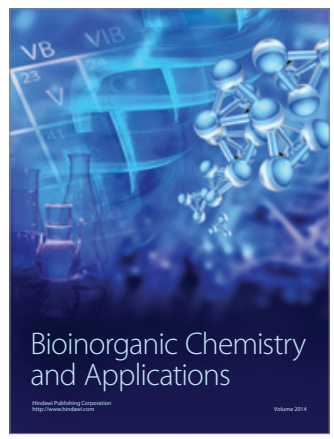

Inorganic Chemistry
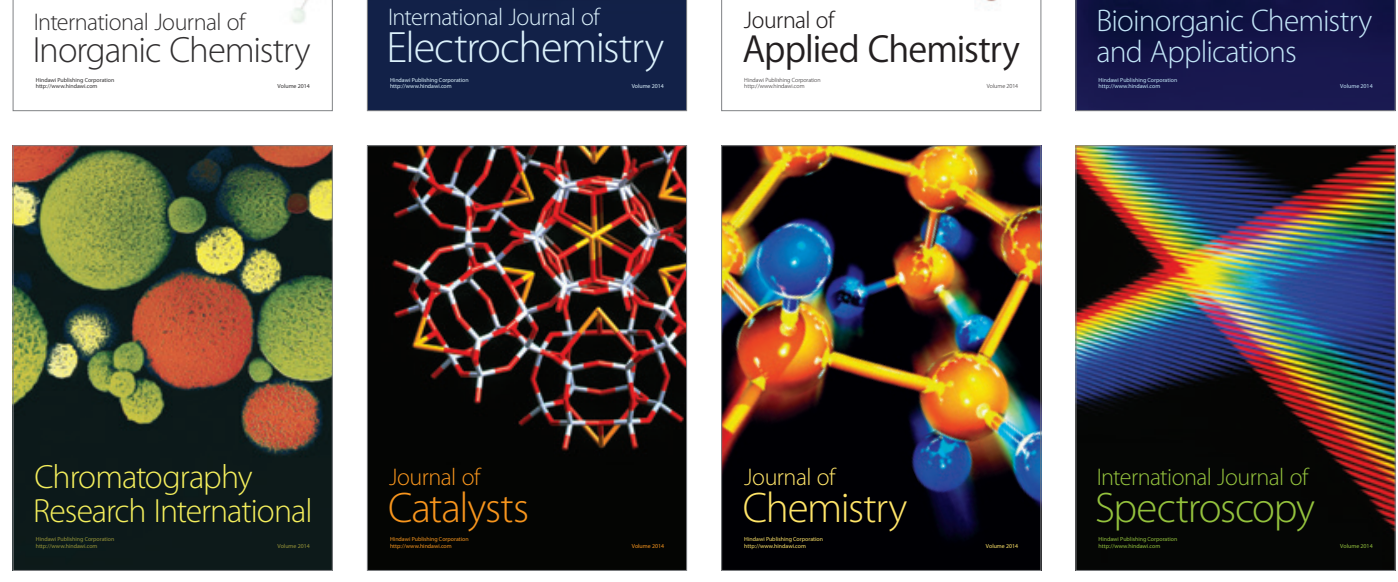